\title{
Cell-mediated immune response in gonococcal infections
}

\author{
FREDERIC A. WYLE, CLAUDIA ROWLETT, AND THOMAS BLUMENTHAL \\ From the Departments of Medicine, University of California, Irvine, California, and \\ Veterans Administration Hospital, Long Beach, California
}

SUMMARY Peripheral blood lymphocyte (PBL) transformation stimulated by gonococcal and meningococcal antigens was studied in 29 men and 21 women with uncomplicated gonorrhoea. The blastogenic responses of PBLs from these men and women were substantially higher than from normal controls. Cross-reactivity between Neisseria gonorrhoeae and Neisseria meningitidis was manifested by the PBL transformation responses in patients with gonorrhoea to non-purified meningococcal antigen (MGC-I). In both male and female patients the PBLs were stimulated by non-purified gonococcal antigen (GC-I) and by non-purified meningococcal antigen. The extent of the blastogenic response in women was much greater than in men. Partial purification of these antigens by gel chromatography resulted in reduced cross-reactive responses to the semi-purified meningococcal antigen (MGC-II). Female patients demonstrated marked stimulation with the semipurified gonococcal antigen (GC-II), while male patients showed slight stimulation with GC-II. It is possible that cell-mediated immunity may act to limit the spread of gonococcal infection beyond the genital mucous membranes.

\section{Introduction}

The marked increase in human gonococcal infection during the past decade (Lucas, 1972) has led to renewed interest in the gonococcus. Many researchers have attempted either to correlate the antigenic structure of Neisseria gonorrhoeae with pathogenic mechanisms (Glynn and Ward, 1970; Buchanan and Gotschlich, 1973; Buchanan et al., 1973) or investigate immunity to the gonococcus (Cohen et al., 1969; Maeland and Larsen, 1971). Several of these studies have been directed towards humoral mechanisms, and some have attempted to refine serological assays (Magnusson and Kjellander, 1965; Watt et al., 1971). Serological assays have generally been of limited value because of the lack of purified antigens and/or because the sensitivity of the assay was so slight. Buchanan et al. (1973) may have resolved one aspect of the serological problem. Their use of gonococcal pili provides a specific and sensitive assay for detecting recent gonococcal infection. While pilated gonococci are associated with virulence in humans (Kellogg et al., 1963, 1968), the presence of circulating anti-pilar antibody does not appear to protect against subse-

Address for reprints: F. A. Wyle, University of California, Irvine California College of Medicine, Long Beach, California 90822, USA Received for publication 1 July 1977 quent infection (Buchanan et al., 1973; Arko et al., 1974).

The broadening knowledge of cell-mediated immunity (CMI) has led to recognition of its role in chronic intracellular infections (Collins, 1971), although its involvement in other types of infection remains uncertain. This situation, coupled with the lack of success in defining protective immunity in antibody studies, has led us to study CMI in gonococcal infection. Previous reports on lymphocyte transformation in gonorrhoea (Kraus et al., 1970; Esquenazi and Streitfeld, 1973; Grimble and McIllmurray, 1973; Kearns et al., 1973) leave no doubt as to the existence of a CMI response in this infection. However, several aspects of the gonococcal CMI response need clarification. The degrees of specificity and the nature of crossreacting antigens are not known and comparisons of CMI responses between men and women with gonorrhoea deserve further exploration. The present study is part of an investigation into the immunology of gonococcal infection and it was undertaken to examine some of these questions. In this report, we relate the results of lymphocyte transformation induced by partially defined gonococcal and meningococcal antigens in men and women with acute gonorrhoea. 
Materials and methods

BACTERIA

Neisseria gonorrhoeae colony type 4 (strain LB49) was a clinical isolate whose identity was verified by standard procedures (Kellogg, 1974). Neisseria meningitidis Group B (strain 99M) was obtained from Dr M. Artenstein of the Walter Reed Army Institute of Research. Stock cultures were maintained in $20 \%$ glycerol in tryptic broth at $-70^{\circ} \mathrm{C}$ until use.

\section{BACTERIAL CULTURE TECHNIQUE}

Each strain was grown overnight in Kellogg's agar medium (Kellogg et al., 1963) at $37^{\circ} \mathrm{C}$ in a $5 \% \mathrm{CO}_{2} /$ $95 \%$ air atmosphere. A heavy loop of this growth was inoculated into a $500 \mathrm{ml}$ flask containing $125 \mathrm{ml}$ of modified Frantz's medium (Frantz, 1942). The composition of this medium was: $1 \%$ casamino acids (Difco), $0.85 \% \mathrm{NaCl}, 0.5 \%$ dextrose, $1 \%$ $\mathrm{NaHPO}_{4} \cdot 7 \mathrm{H}_{2} 0,0 \cdot 0022 \%$ cystein- $\mathrm{HCl}, 0 \cdot 06 \% \mathrm{MgSO}_{4}$ $\cdot 7 \mathrm{H}_{2} \mathbf{0}, 0.01 \% \mathrm{KCl}, 0.1 \%$ yeast extract (BBL), and $1 \%$ IsoVitaleX (BBL). Broth cultures were incubated in a shaker water bath at $37^{\circ} \mathrm{C}$ for six hours, inoculated into 10 litres of modified Frantz's medium in a microferm fermentor (New Brunswick Scientific Co.) and grown for 18 hours at $37^{\circ} \mathrm{C}$ with aeration (5L air $/ \mathrm{min}$ ) and stirred at $200 \mathrm{rev} / \mathrm{min}$. This culture technique yielded concentrations for the $N$. gonorrhoeae strain of approximately $1 \times 10^{8}$ cells $/ \mathrm{ml}$ and for the $N$. meningitidis strain of approximately $5 \times 10^{8}$ cells $/ \mathrm{ml}$. The cells were harvested by continuous flow centrifugation at $15000 g \times 4$ hours in an RC2B refrigerated centrifuge (Ivan Sorvall) and washed twice with $0.85 \%$ $\mathrm{NaCl}$.

\section{ANTIGEN EXTRACTION TECHNIQUE}

A modification of the Ribi ether extraction technique (Ribi et al., 1961) was used. Two volumes of cold $\left(4^{\circ} \mathrm{C}\right)$ ethyl ether were added to a $10 \% \mathrm{mass} / \mathrm{vol}$. suspension of the bacterial cells in $0.85 \% \mathrm{NaCl}$. This suspension was stirred for 24 hours at $4^{\circ} \mathrm{C}$ and then transferred to a separatory funnel for phase

- separation at $4^{\circ} \mathrm{C}$ for 18 hours. The lower aqueous phase was drained off and the residual ether removed by aeration. The saline extract containing isolated bacterial outer membranes was separated from the residual cells by centrifugation $(8000 \times g ; 20 \mathrm{~min})$. This supernatant solution was dialysed against $\mathbf{5 0}$ volumes of distilled water and lyophilised. The lyophilised extract is henceforth denoted as crude antigen. A solution of crude antigen was prepared at a concentration of $1 \mathrm{mg} / \mathrm{ml}$ in $30 \mathrm{mmol} / 1 \mathrm{Tris}-\mathrm{HCl}$, pH 7.8 (Tris buffer), and enzyme treated by incubation with ribonuclease $(5 \mu \mathrm{g} / \mathrm{ml})$ and deoxy- ribonuclease $(0.5 \mu \mathrm{g} / \mathrm{ml})$ for four hours at $37^{\circ} \mathrm{C}$. Ascending gel filtration chromatography was performed with a $2.5 \times 60 \mathrm{~cm}$ column of Sephadex G-50 equilibrated with Tris buffer. Six millilitres of enzyme digested crude antigen was applied to the column and eluted with Tris buffer. The eluent was monitored at $260 \mathrm{~nm}$ and $280 \mathrm{~nm}$ by a UA-4 absorbance monitor (ISCO). Ten millilitre fractions were collected and those under the first peak were pooled, dialysed against distilled water, and lyophilised. This henceforth is referred to as semipurified antigen.

\section{CHEMICAL ANALYSIS}

The composition of the antigens was determined as follows: protein concentration by the Lowry method (Lowry et al., 1951) using bovine serum albumin as the standard, carbohydrate by the anthrone reaction (Williams and Chase, 1968a) using dextrose as the standard, sialic acid concentration by the resorcinol procedure (Williams and Chase, 1968b) using $\mathrm{N}$-acetyl neuraminic acid (Sigma) as the standard, and nucleic acid by the $280 \mathrm{~nm} / 260 \mathrm{~nm}$ absorbance ratio (Colowick and Kaplan, 1957).

\section{SUBJECTS}

The study group consisted of 29 men and 21 women with culture-proved uncomplicated gonorrhoea They had presented themselves to the Santa Ana? Venereal Disease Clinic or the University of Southern California-Los Angeles County Medical Center Venereal Disease Clinic because they had symptoms or were contact referrals. Thirty millilitres of venous blood was collected from each patient in heparinised vacutainers (No. 4792, Becton-Dickinson). All the men exhibited symptomatic gonococcal urethritis; the mean duration of symptoms before blood sampling was seven days with a total range of 1-21 days. Nine of the 21 women were symptomatic with a mean duration of symptoms of 14 days and a range of 3-20 days. The remaining 12 women were asymptomatic; the duration of infection before blood sampling for these patients was estimated from the date of contact referral as 17 days with a range of 12-30 days. A detailed history was obtained for each patient including the number of previous gonococcal infections. The control group consisted of 10 men and 10 women who were medical employees from the Long Beach Veterans Administration Hospital, all of whom denied a history of gonorrhoea.

LYMPHOCYTE TRANSFORMATION STUDIES Peripheral blood lymphocytes (PBLs) were separated from venous blood using the gel sedimentation 
technique of Coulson and Chalmers (1964). Viability, as assessed by trypan blue dye exclusion, was between 90 and $95 \%$. The PBLs were adjusted to a concentration of $1 \times 10^{6}$ lymphocytes $/ \mathrm{ml}$ in Earle's minimal essential medium (MEM) (Gibco) containing $10 \%$ autologous plasma, 100 units penicillin/ $\mathrm{ml}$, and $100 \mu \mathrm{g}$ streptomycin $/ \mathrm{ml}$. Triplicate PBL cultures were performed in slanted, loosely capped $16 \times 100 \mathrm{~mm}$ tubes. Each culture contained $1.0 \mathrm{ml}$ of lymphocyte suspension and was incubated for six days at $37^{\circ} \mathrm{C}$ in a $5 \% \mathrm{CO}_{2} / 95 \%$ air atmosphere. Either $0.2 \mathrm{ml}$ of phytohaemagglutinin-P (PHA) $(200 \mu \mathrm{g} / \mathrm{ml})$ or $0.2 \mathrm{ml}$ of antigen $(1 \mathrm{mg} / \mathrm{ml})$ was added to the cultures as a T-cell stimulant. Lymphocyte transformation was assessed by measuring incorporation of tritiated thymidine ( $\left.{ }^{3} \mathrm{H}-\mathrm{TdR}\right)$ into DNA. Each culture was pulsed on day 6 for four hours with $1 \mu \mathrm{Ci}{ }^{3} \mathrm{H}-\mathrm{TdR}(6 \mathrm{Ci} / \mathrm{mmol} / \mathrm{l}$; Schwarz Mann). Radioactively labelled cultures were washed with cold saline, precipitated with $10 \%$ trichloracetic acid (TCA), and poured on to glass fibre filters (Type E, Gelman) on a suction apparatus. The filters were washed with $5 \mathrm{ml}$ cold TCA followed by $10 \mathrm{ml}$ of methanol and placed on scintilation vials. One-half millilitre of NCS solubiliser (Amersham Searle) and $10 \mathrm{ml}$ of a scintillation cocktail (5.0 g 2,5 diphenyloxaxole (PPO) and $0.4 \mathrm{~g} \mathrm{1,4}$ bis-2-(5-phenyloxaxolyl)-benzene (POPOP) per litre toluene) were added to each vial. Radioactivity was measured in a Packard Tri-Carb 2450 (Packard Instruments) scintillation spectrometer.

\section{CALCULATIONS AND STATISTICS}

The results of this study are expressed in the form of a transformation index (TI), which was calculated by dividing the mean of triplicate antigen-stimulated cultures by the mean of triplicate unstimulated control cultures. As it was not possible to assume definitively that the population in this study was normally distributed, the sample groups were compared using a non-parametric technique-the median test. The median test measures the difference in central tendencies between two independent groups. The significance of the sample distributions as found with the median test was determined by $\chi^{2}$ analysis corrected for continuity and verified by Fisher's exact probability test.

\section{Results}

\section{LYMPHOCYTE TRANSFORMATION WITH} CRUDE ANTIGEN

PBLs from the patients with gonorrhoea and normal controls were tested with crude gonococcal and crude meningococcal antigens. Preliminary experiments indicated that antigen concentrations of 1.0 $\mathrm{mg} / \mathrm{ml}$ were optimal in our assay. The responses to the crude gonococcal antigen (GC-I) are summarised in Fig. 1 and Table 1. PBLs from women with

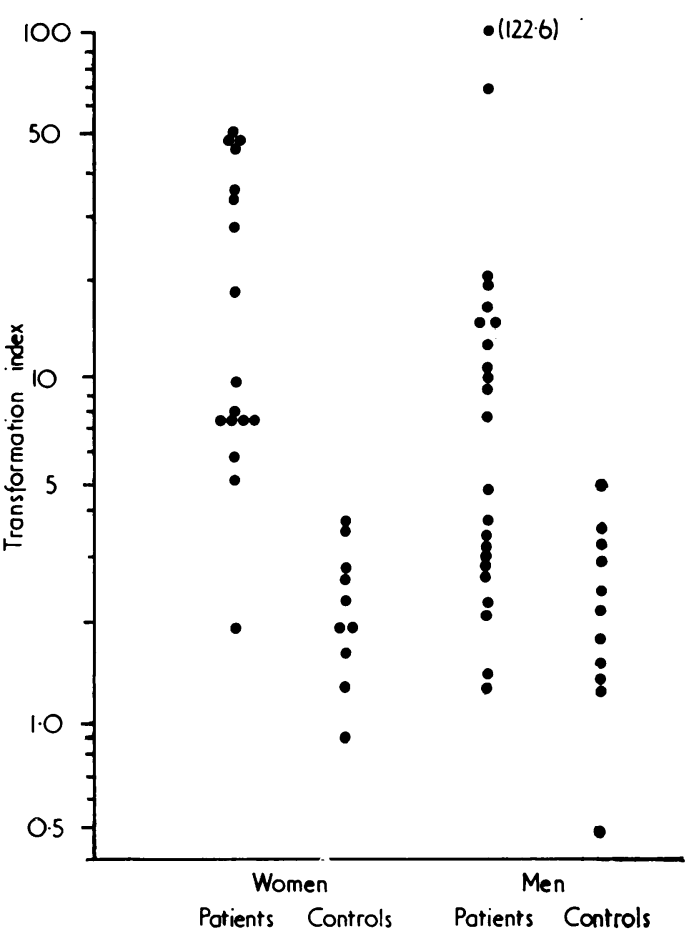

Fig. 1 Peripheral blood lymphocyte transformation responses to crude gonococcal antigen in men and women with uncomplicated gonorrhoea and in normal subjects. Response shown in terms of transformation index (TI). Each symbol represents the mean of triplicate tests on one individual.

Table 1 Transformation index (crude antigen)

\begin{tabular}{|c|c|c|c|c|}
\hline Crude & Subject group & No. & Median & Range \\
\hline & $\begin{array}{l}\text { Female patients } \\
\text { Female controls } \\
\text { Male patients } \\
\text { Male controls }\end{array}$ & $\begin{array}{l}17 \\
10 \\
23 \\
10\end{array}$ & $\begin{array}{l}9 \cdot 9 \\
2 \cdot 1 \\
7 \cdot 9 \\
2 \cdot 0\end{array}$ & $\begin{array}{l}(1 \cdot 9-52 \cdot 3) \\
(0 \cdot 9-3 \cdot 8) \\
(1 \cdot 3-122 \cdot 6) \\
(0.5-4.9)\end{array}$ \\
\hline al & $\begin{array}{l}\text { Female patients } \\
\text { Male patients } \\
\text { Male controls }\end{array}$ & $\begin{array}{r}7 \\
10 \\
16 \\
10\end{array}$ & $\begin{array}{r}26 \cdot 1 \\
3 \cdot 9 \\
8 \cdot 6 \\
3 \cdot 6\end{array}$ & $\begin{array}{l}(13 \cdot 2-68 \cdot 2)_{\mathrm{P}}<0.001^{*} \\
(0 \cdot 8-9 \cdot 2) \\
(1 \cdot 0-83.0) \\
(0 \cdot 7-10.7)\end{array}$ \\
\hline
\end{tabular}

*A significant difference exists between the central tendencies of the two groups as determined by the median test and $\chi^{2}$ analysis.

gonorrhoea showed a significantly greater blastogenic response to GC-I antigen than did those from female controls $(P<0.001)$. Of the 17 female patients tested with GC-I antigen, $94 \%$ produced responses greater than the highest $\mathrm{TI}$ found in the female control group. PBLs from men with gonorrhoea 
stimulated with GC-I antigen displayed greater responses than did those from male controls $(P<0.025)$. In the group of patients, $52 \%$ of the 23 men tested with GC-I antigen demonstrated blastogenic responses greater than the highest TI found in the male control group.

Figure 2 and Table 1 summarise the PBL responses to the crude meningococcal antigen (MGC-I). With

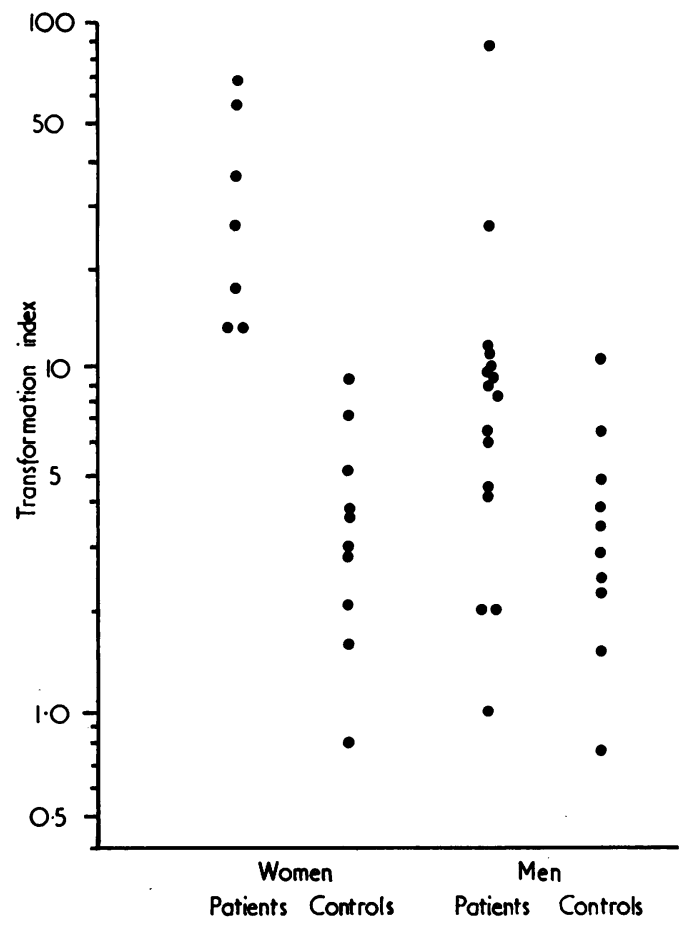

Fig. 2 Peripheral blood lymphocyte transformation responses to crude meningococcal antigen in men and women with uncomplicated gonorrhoea and in normal subjects. Response shown in terms of transformation index $(T I)$. Each symbol represents the mean of triplicate tests on one individual.

PBLs from women patients there was also a very significant difference in the magnitude of response compared with that for female controls $(P<0.001)$. All of the seven female patients had blastogenic responses greater than those of the control group. Men with gonorrhoea showed a somewhat greater response to MGC-I than did male controls $(\mathrm{P}<$ 0.025 ). Only $13 \%$ of the 16 male patients tested with MGC-I produced blastogenic responses greater than the highest response in the male control group.

No correlation could be made between the number of previous gonococcal infections and the degree of blastogenic response. Another aspect was the number of non-responders; a non-responder is defined as an individual whose TI response was not twice the median of his/her control group for a given antigen. The incidence of non-responders was much greater among male patients than female patients (Table 2).

Table 2 Incidence of non-responders* to gonococcal crude antigen and meningococcal crude antigen

\begin{tabular}{lcc}
\hline & \multicolumn{2}{l}{ Crude antigen } \\
\cline { 2 - 3 } Patients & Gonococcal (\%) & Meningococcal (\%) \\
\hline Women & 6 & 0 \\
Men & 43 & 44 \\
\hline
\end{tabular}

*Non-responder $=$ an individual patient whose transformation index is less than twice the median of the control group. Results are expressed as the total percentage of patients classified as nonresponders.

LYMPHOCYTE TRANSFORMATION WITH SEMIPURIFIED ANTIGEN

Partial purification of each crude antigen was effected by ribonuclease and deoxyribonuclease treatment together with gel filtration chromatography. Figure 3 illustrates the elution pattern for the semi-purified gonococcal antigen (GC-II); the pattern for the semi-purified meningococcal antigen (MGC-II) was virtually identical. Using antisera produced in rabbits by immunisation with intact gonococci or meningococci, antigens could be detected only in the first elution peak by the methods of immunodiffusion and indirect haemagglutination inhibition. As shown in Fig. 3, the first peak is primarily protein in composition. The $280 \mathrm{~nm} / 260$ $\mathrm{nm}$ ratios indicated that the second peak is largely nucleic acid. Chemical analysis of the crude and semi-purified antigens is shown in Table 3.

Table 3 Chemical composition of antigens (\%)

\begin{tabular}{lllll}
\hline Antigens & Protein & $\begin{array}{l}\text { Carbo- } \\
\text { hydrate }\end{array}$ & $\begin{array}{l}\text { Sialic } \\
\text { acid }\end{array}$ & $\begin{array}{l}\text { Nucleic } \\
\text { acid }\end{array}$ \\
\hline $\begin{array}{l}\text { Gonococcal } \\
\text { crude }\end{array}$ & $41 \cdot 1$ & 2.9 & 1.5 & 44 \\
$\begin{array}{c}\text { Gonococcal } \\
\text { semi-purified }\end{array}$ & 82.0 & 2.1 & 0 & 1 \\
$\begin{array}{c}\text { Meningococcal } \\
\text { crude }\end{array}$ & 47.3 & 5.0 & 7.1 & 22 \\
$\begin{array}{c}\text { Meningococcal } \\
\text { semi-purified }\end{array}$ & 85.6 & 2.0 & 0.9 & 1 \\
\hline
\end{tabular}

The results of testing GC-II and MGC-II antigens in the lymphocyte transformation assay are summarised in Fig. 4 and Table 4. PBLs from female patients responded to GC-II antigen compared with the control group $(\mathrm{P}<0.005)$; of the 10 women tested with GC-II antigen $80 \%$ had blastogenic responses greater than any member of the control group. PBLs from male patients showed a slightly 


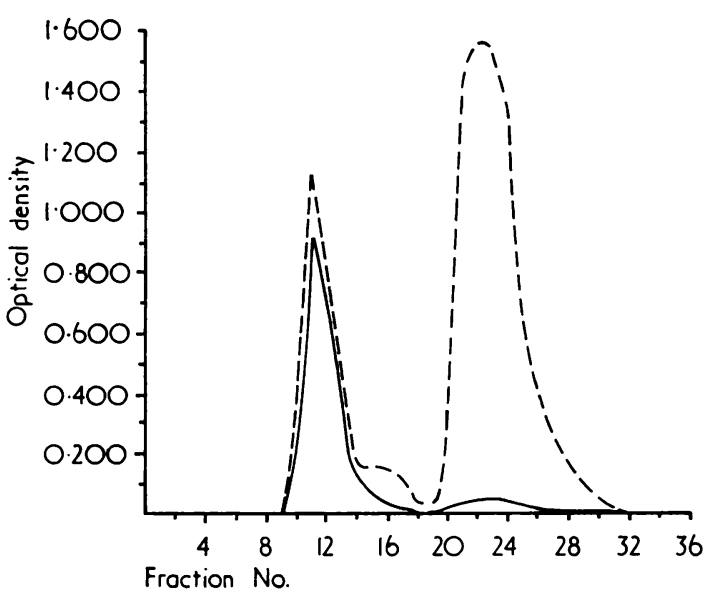

Fig. 3 Purification of RNAse and DNAse treated crude gonococcal antigen by Sephadex G-50 chromatography. $6 \mathrm{ml}$ of antigen were applied to a column of Sephadex G-50 $(2.5 \times 60 \mathrm{~cm})$ and were eluted by $30 \mathrm{mmol} / \mathrm{l}$

Tris- $\mathrm{HCl}, \mathrm{pH} 7 \cdot 8$. Collected fractions were $10 \mathrm{ml}$. Void volume was approximately $120 \mathrm{ml}$. $(--)=$ absorbance at $260 \mathrm{~nm}$.

$(-)=a b s o r b a n c e$ at $700 \mathrm{~nm}$ (Lowry protein).

greater response to GC-II antigen than did the control group $(\mathrm{P}<0.05)$. Of the eight male patients tested with GC-II antigen $75 \%$ had blastogenic responses greater than any member of the control group. In the patients, neither the men nor the women demonstrated a significant blastogenic response to MGC-II antigen compared with controls, although a few individuals displayed high stimulation with this antigen.

Table 4 Transformation index (semi-purified antigens)

\begin{tabular}{|c|c|c|c|c|c|}
\hline $\begin{array}{l}\text { Antigens } \\
\text { (semi-purified) }\end{array}$ & Subject group & No. & Median & Range & \\
\hline $\mathrm{cal}$ & $\begin{array}{l}\text { Female patients } \\
\text { Controls* } \\
\text { Male patients }\end{array}$ & $\begin{array}{r}10 \\
6 \\
9\end{array}$ & $\begin{array}{r}10 \cdot 0 \\
2 \cdot 0 \\
5 \cdot 3\end{array}$ & $\begin{array}{l}(3 \cdot 5-31 \cdot 3) \\
(0 \cdot 7-4 \cdot 0) \\
(1 \cdot 1-39 \cdot 2)\end{array}$ & $\begin{array}{l}P<0.005 \dagger \\
P<0.05 \dagger\end{array}$ \\
\hline Ieningococcal & $\begin{array}{l}\text { Female patients } \\
\text { Controls* } \\
\text { Male patients }\end{array}$ & $\begin{array}{l}7 \\
6 \\
9\end{array}$ & $\begin{array}{l}6 \cdot 8 \\
2 \cdot 7 \\
3 \cdot 3\end{array}$ & $\begin{array}{l}(1 \cdot 8-13 \cdot 2) \\
(2 \cdot 0-7 \cdot 4) \\
(1 \cdot 1-39 \cdot 2)\end{array}$ & $\begin{array}{l}P>0.05 \ddagger \\
P>0.05 \ddagger\end{array}$ \\
\hline
\end{tabular}

* Because of the limited quantity of semi-purified antigen available and the fact that the male and female control groups produced virtually identical results with the crude antigen (Table 1, Figs 1 and $2)$, the control values for men and women are combined.

†A significant difference exists between the central tendencies of the two groups as determined by the median test and $\chi^{2}$ analysis.

¥A significant difference does not exist between the central tendencies of the two groups as determined by the median test and $\chi^{2}$ analysis.

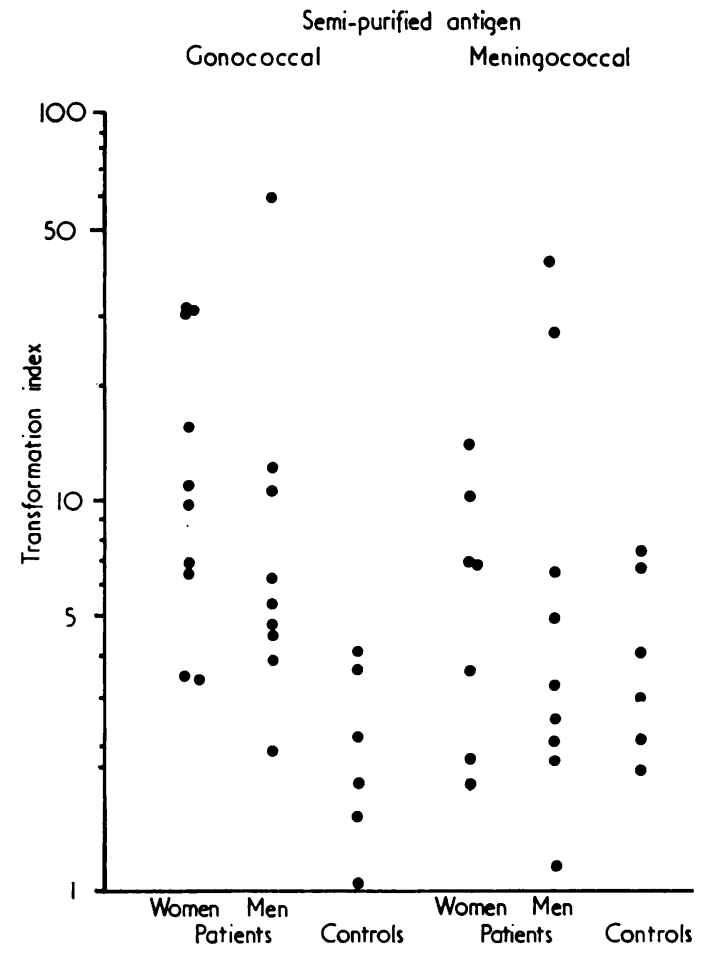

Fig. 4 Peripheral blood lymphocyte responses to semi-purified gonococcal and meningococcal antigen in men and women with uncomplicated gonorrhoea and in normal subjects. Response shown in terms of transformation index (TI). Each symbol represents the mean of triplicate tests on one individual.

\section{BLASTOGENIC RESPONSE PATTERNS}

Both male and female patients exhibited an extremely broad range of blastogenic responses to gonococcal and meningococcal antigens. By comparison, control subjects demonstrated lower and more uniform responses. As a group, the female patients displayed greater CMI responses than did male patients. Both male and female patients had similar response patterns to GC-I and MCG-I antigens. Female patients showed a significant response to GC-II antigen, while male patients showed slight stimulation with GC-II. Both male and female patients showed only slight stimulation with MGC-II antigen.

\section{Discussion}

Problems with assay sensitivity and specificity described in CMI studies of gonococcal infection (Kraus et al., 1970; Esquenazi and Streitfeld, 1973; Grimble and McIllmurray, 1973; Kearns et al., 1973) 
are similar to those with antibody assays-namely, impure antigens. While the antigens used in our study were only partially purified, they were defined and did elicit marked responses. Even considering the many factors that may influence the degree of blastogenic response, including patient population differences, in many cases the transformation indices found in our study were considerably greater than those previously reported. Furthermore, our results showed that a semi-purified gonococcal protein antigen stimulated a blastogenic response. The heterologous cross-reactions seen when MGC-I antigen was used in our lymphocyte transformation assay were not unexpected. Descriptions of serological cross-reactions between gonococci and meningococci have been reported previously (Danielsson, 1965; Buchanan et al., 1973). What was surprising was the degree of cross-reactivity. Immunodiffusion and indirect haemagglutination inhibition studies in our laboratory (unpublished data) indicated that our crude preparations shared several antigens. These serological studies showed that partial purification removed some of the crossreactive antigens. Our lymphocyte transformation results seemed to verify this as shown by the much lower response of patients' PBLs to the MGC-II antigen, but not the GC-II antigen.

Comparisons of lymphocyte transformation between men and women with gonorrhoea have not previously been made. There are precedents for the substantially higher female response rate seen in this study. Higher response rates for women in gonococcal serological assays have been reported (Lee and Schmale, 1970; Watt et al., 1971). The traditional explanation is that as infection with $N$. gonorrhoeae in women tends to be asymptomatic (Holmes et al., 1971), the duration of infection is much longer and thus produces a greater antibody response.

This study has verified the lymphocyte transformation response in gonococcal infection. We feel it would be premature to dismiss such findings as merely concomitants of infection and not representative of protective immunity. The host defences against uncomplicated and complicated gonococcal infections are complex. They remain poorly understood partly because traditional concepts of protective immunity have been found not to apply. It is possible that CMI may have a functional role in preventing dissemination of gonococcal infection beyond the primary genital mucuous membrane sites. We feel this possibility deserves further investigation.

We wish to thank A. Mathies and A. Renteria of the University of Southern California, Los Angeles
County Medical Center and T. Albert and P. Burrell of the Orange County Health Department without whose co-operation this study would not have been possible. We wish also to thank $T$. Cesario for his comments in the preparation of this manuscript and P. Stinson for her collaboration on the statistical analysis.

This investigation was supported in part by US Army R \& D Contract, DADA-17-72-DG-2076 and by the Clinical Investigatorship Program of the Veterans Administration.

\section{References}

Arko, R. J., Kraus, S. J., Brown, W. J., Buchanan, T. M., and Kuhn, U. S. G. (1974). Neisseria gonorrhoeae: Effects of systemic immunization on resistance of chimpanzees to urethral infection. Journal of Infectious Diseases, 130, 160-164.

Buchanan, T. M., and Gotschlich, E. C. (1973). Studies on gonococcus infection. III. Correlation of gonococcal colony morphology with infectivity for the chick embryo. Journal of Experimental Medicine, 137, 421-439.

Buchanan, T. M., Swanson, J., Holmes, K. K., Kraus, S. J., and Gotschlich, E. C. (1973). Quantitative determination of antibody to gonococcal pili. Journal of Clinical Investigation, 52, 2896-2909.

Cohen, I. R., Kellogg, D. S., Jr, and Norins, L. C. (1969). Serum antibody response in experimental human gonorrhoea: Immunoglobulins G, A, and M. British Journal of Venereal Diseases, 45, 325-327.

Collins, F. M. (1971). Mechanisms in antimicrobial immunity. Journal of the Reticuloendothelial Society, 10, 58-99.

Colowick, S. P., and Kaplan, N. O. editors (1957). Methods in Enzymology, volume 3, pp. 451-454. Academic Press: New York.

Coulson, A. S., and Chalmers, D. G. (1964). Separation of viable lymphocytes from human blood. Lancet, 1, 468-469.

Danielsson, D. (1965). The demonstration of $N$. gonorrhoeae with the aid of fluorescent antibodies. IV. Studies of immunofluorescence and double diffusion-in-gel technique on the antigenic relationship between N. gonorrhoeae and other Neisseria strains. Acta pathologica et microbiologica Scandinavica, 64, 267-276.

Esquenazi, V., and Streitfeld, M. M. (1973). Transformation of lymphocytes in gonorrhea before and after therapy. Infection and Immunity, 8, 503-509.

Frantz, I. D., Jr (1942). Growth requirement of the meningococcus. Journal of Bacteriology, 43, 757-761.

Glynn, A. A., and Ward, M. E. (1970). Nature and heterogeneity of the antigens of Neisseria gonorrhoeae involved in the serum bactericidal reaction. Infection and Immunity, 2, 162-168.

Grimble, A. S., and McIllmurray, M. B. (1973). Cell-mediated immune response in gonorrhoea. British Journal of Venereal Diseases, 49, 446-449.

Holmes, K. K., Counts, G. W., and Beaty, H. N. (1971). Disseminated gonococcal infection. Annals of Internal Medicine, 74, 979-993.

Kearns, D. H., Seibert, G. B., O'Reilly, R., Lee, L., and Logan, L. (1973). Paradox of the immune response to uncomplicated gonococcal arthritis. New England Journal of Medicine, 289, 1170-1174.

Kellogg, D. S., Jr (1974). Neisseria gonorrhoeae (gonococcus). In Manual of Clinical Microbiology, second edition, pp. 124-129. Edited by E. H. Lenette, E. H. Spaulding and J. P. Truant. American Society for Microbiology: Washington DC.

Kellogg, D. S., Jr, Cohen, I. R., Norins, L. C., Schroeter, A. L., and Reising, G. (1968). Neisseria gonorrhoeae: II. Clonal variations and pathogenicity during 35 months in vitro. Journal of Bacteriology 96, 596-605.

Kellogg, D. S., Jr, Peacock, W. L., Jr, Deacon, W. E., Brown, L., and Pirkle, C. I. (1963). Neisseria gonorrhoeae: I. Virulence genetically linked to clonal variation. Journal of Bacteriology, 85, 1274-1279. 
Kraus, S. J., Perkins, G. H., and Geller, R. C. (1970). Lymphocyte transformation in repeated gonococcal urethritis. Infection and Immunity, 2, 655-658.

Lee, L., and Schmale, J. D. (1970). Identification of a gonococcal antigen important to the human immune response. Infection and Immunity, 1, 207-208.

Lowry, O. H., Rosebrough, N. A., Farr, A. L., and Randall, R. J. (1951). Protein measurement with the Folin phenol reagent. Journal of Biological Chemistry, 193, 265-271.

Lucas, J. B. (1972). The national venereal disease problem. Medical Clinics of North America, 56, 1073-1086.

Maeland, J. A., and Larsen, B. (1971). Human serum antibodies reacting with endotoxin from Neisseria gonorrhoeae. British Journal of Venereal Diseases, 47, 269-272.

Magnusson, B., and Kjellander, J. (1965). Gonococcal complementfixation test in complicated and uncomplicated gonorrhoea. British Journal of Venereal Diseases, 41, 127-131.
Ribi, E., Haskins, W. T., Landy, M., and Milner, K. C. (1961). Preparation and host-reactive properties of endotoxin with low content of nitrogen and lipid. Journal of Experimental Medicine, 114, 647-663.

Watt, P. J., Ward, M. E., and Glynn, A. A. (1971). A comparison of serological tests for the diagnosis of gonorrhoea. British Journal of Venereal Diseases, 47, 448-451.

Williams, C. A., and Chase, M. W. editors (1968a). Methods in Immunology and Immunochemistry, volume 2, pp. 288-289. Academic Press: New York.

Williams, C. A., and Chase, M. W. editors (1968b). Methods in Immunology and Immunochemistry, volume 2, pp. 303-304. Academic Press: New York. 